\title{
Photofading of Derivatives of Paraben (PHB) by AM1 and PM3 Methods: A Theoretical Study
}

\author{
Krzysztof Wojciechowski1 ${ }^{*}$, Lucjan Szuster ${ }^{2}$ \\ ${ }^{1}$ Institute of Environmental Engineering and Building Installations, Technical University of Łódź, Łódź, Poland \\ ${ }^{2}$ Leather Research Institute, Łódź, Poland \\ Email: *krzwojc@p.lodz.pl
}

How to cite this paper: Wojciechowski, K. and Szuster, L. (2019) Photofading of Derivatives of Paraben (PHB) by $\mathrm{AM} 1$ and PM3 Methods: A Theoretical Study. Computational Chemistry, 7, 39-50. https://doi.org/10.4236/cc.2019.72003

Received: October 12, 2018

Accepted: April 20, 2019

Published: April 23, 2019

Copyright (c) 2019 by authors and Scientific Research Publishing Inc. This work is licensed under the Creative Commons Attribution International License (CC BY 4.0).

http://creativecommons.org/licenses/by/4.0/

(c) (i) Open Access

\begin{abstract}
Calculations of chemical structures and photofading of parabens (PHB-4 hydroxybenzoic acid), which are p-hydroxybenzoic acid alkyl esters were performed. These compounds are used as preservatives for the substances used in cosmetics. The reactivity of these derivatives with an oxidant-singlet oxygen-have been tested with a theoretical method of frontier orbitals. All-valence molecular orbital methods, AM1 and PM3, have been used to calculate frontier electron density for higher occupied HOMO and lower unoccupied LUMO orbitals, which might be sensitive to an electrophilic (with singleton oxygen atom $\left.{ }^{1} \mathrm{O}_{2}\right)$ or nucleophilic $\left(\mathrm{O}_{2}{ }^{--}\right.$superoxide anion radical) attack at a particular atom in a molecule. Using AM1 and PM3, we calculated the reactivity $f_{r}^{E(N)}$, superdelocalisability $S_{r}^{E(N)}$ and electron density distributions. The obtained superdelocalisability rates allow you to explain the fastness values in different chemical molecules. The structure of parabens (PHB) was optimized by MM+, DM, AM1 or PM3, to achieve constant energy values at a convergence criterion of 0.01 $\mathrm{kcal} / \mathrm{mol}$. The performed calculations indicate that the electrophilic oxidation reaction should take place in the aromatic ring in the 2-position to the hydroxyl residue of $\mathrm{PHB}$, whereas the superoxide radical reaction occurs mainly on the alkyl residues of the ester group. The reaction may take place according to superoxide mechanism or 1,2-addition, where the higher superdelocalisability values $S^{N}$ are located on neighboring atoms in aromatic systems.
\end{abstract}

\section{Keywords}

Photofading of Parabens, All-Valence MO Calculation, Orbital Frontier Electron Density, Electrophilic and Nucleophilic Attack, Theoretical Study 


\section{Introduction}

Parabens are the esters of para-hydroxybenzoic acid and they are the most common preservatives in use due to their efficacy and safety; their relatively non-irritating, non-sensitizing characteristics. Parabens are added to cosmetics, foods and pharmaceutical products. They are antifungal and antibacterial; more active against Gram-positive than Gram-negative bacteria. The synergy between esters has been reported and it is very profitable to use their combinations. The mechanism of antibacterial properties of parabens has not been fully explained. Probably, they are inhibitors of the nucleic acid synthesis of DNA and RNA or inhibit enzymes necessary for the proper functioning of bacterial cells such as ATP and phosphotransferase.

The photostability of the chemicals is dependent on many factors, including the chemical structure of the molecules that determined the reactivity of the excited states as a result of the action of light [1] [2] [3] [4]. Till now, there was no research on light fastness of the paraben group of the p-hydroxybenzoic acid (PHB) ester derivatives, used as conservatives for cosmetics. Their protective effect is related to their oxidation, which is quicker than the oxidation of a given chemical compound which it is protecting. The reaction rate depends on the length of the aliphatic chain of the ester residue.

Understanding the effect that substituents have on the parabens lightfastness has a significant meaning or their appropriate applications and skin hazard as regards the products of decomposition of cosmetics.

Molecular orbital calculations can provide an insight into the process of parabens fading in the presence of light depending on their electronic properties [5]. Numerous studies have been done to predict the addition of singlet oxygen e.g. in dyes containing azo moieties [6] [7] [8].

The frontal orbitals theory suggests that the atoms in the primary HOMO state of high electron density are susceptible to the electrophilic attack of the singlet oxygen atom ${ }^{1} \mathrm{O}_{2}$ and they have high activity coefficients $f_{r}^{E}$. We similarly define the LUMO $f_{r}^{N}$ electron state of atoms or bonds, where the molecule undergoes a nucleophilic reaction with $\mathrm{O}_{2}{ }^{--}$. The place of electro- or nucleophilic attack is the atom, where the calculated $S_{r}^{E(N)}$ values are the highest [1]. The reliability of the results obtained in this way has been confirmed during numerous tests on organic dyes [9]. The local reactivity indices are useful tools for predicting the most likely reaction sites [10].

Superdelocalisability $S_{r}^{E(N)}$ determines the relative propensity of compounds toward electrophilic and nucleophilic attack respectively, on the dye molecule, and are calculated with the following equation:

$$
S_{r}^{E(N)}=f_{r}^{E(N)} / E_{\text {HOMO(LUMO) }}
$$

where $f_{r}^{E(N)}$ is electron density measure in the ground/excited state on the $r$-atom, $\mathrm{E}_{\text {номо(LUмO) }}$-energy of HOMO or LUMO orbital. It allows comparing the reactivity of corresponding atoms in different molecules [8] [11] [12].

Atoms with small $f_{r}$ values possess high resistance to photochemical reactions, 
while those with larger $f_{r}$ values exhibit poor lightfastness.

The AM1 and PM3 predictive methods allowing to predict electron properties, geometric structure, total energy and formation heat of compounds from period 1 and 2 of the Periodic Table. They are Self-Consistent Fields (SCF) methods. AM1 is an improvement of the MNDO method and is one of the most accurate method, used for organic molecules. PM3 differs from AM1 only in the values of the parameters, which were derived by comparing a larger number and wider variety of experimental versus computed molecular properties.

We based our analysis on the following assumptions [1]:

- the site of the electrophilic attack with singlet oxygen ${ }^{1} \mathrm{O}_{2}$ is the atom with the highest values $f_{r}^{N}$ and $S_{r}^{N}$. For nucleophilic attack with superoxide anion radical $\mathrm{O}_{2}{ }^{--}$, it is the atom with the highest value of $f_{r}^{N}$ and $S_{r}^{N}$.

- if the attack is to be effective, the difference in energy of the HOMO state for factors $\mathrm{E}$ or $\mathrm{N}$ should not be less than $\approx 6 \mathrm{eV}$.

- $S_{r}^{E}$ i $S_{r}^{N}$ determine the probability and relative easiness of the electro- or nucleophilic attack on the respective atom of the molecule.

Apart from the above, to understand lightfastness researchers have primarily addressed the reactive site in a particular molecule. The results of MO calculation have been used to propose a possible mode of degradation of parabens when exposed to light.

The chemical reaction occurs at the position where mutual overlap of their frontier orbitals is most effective. The results of the MO calculation have been used to obtain the HOMO and LUMO frontier electron density. This allowed to determine the site of oxidation of parabens by singlet oxygen ${ }^{1} \mathrm{O}_{2}$ [7] [13] or superoxide anion radical $\mathrm{O}_{2}{ }^{--}$.

In our research, we focused on the use of AM1 and PM3 MO to calculate the probable site of an electrophilic or nucleophilic attack on a compound molecule. The mechanism of oxidation reaction with singlet oxygen of $\mathrm{C}=\mathrm{C}$ bonds with MINDO/3 method has been described by Dewar and Thiele [14] et al. [1] [8] [11]. In the most frequently performed $\mathrm{MO}$ analysis of dye properties, it is assumed that the molecules are in the gaseous phase. In line with the frontal orbitals theory, only the interactions between the HOMO of the paraben and the LUMO of the oxidant [15] are included in the analysis.

We have calculated electron density of frontal orbitals in the ground HOMO state and excited LUMO state of the oxidant.

The appropriate measure to determine the activity of singlet oxygen in the electrophilic reaction or a radical in a nucleophilic reaction is the frontier charge density $\left(\mathrm{Q}_{\mathrm{f}}\right)$ for highest occupied molecular orbital HOMO and for lowest unoccupied molecular orbital LUMO [7].

$$
Q_{f}^{j}=2 \sum_{i=1}^{n} c_{j i}^{2}
$$

where $c_{j i}$ are the coefficients of frontier orbital $i$ atom $j$ (HOMO or LUMO), $Q_{f}^{j}$ - frontier charge density. 
The ${ }^{1} \mathrm{O}_{2}$ can add to the double bonds via the ene reaction or cycloaddition, as seen in synthetic dyes [16]. In such case, a good correlation is obtained between the oxidation rate and the sum $S_{m, n}^{E}$ of the values $f_{r}^{E}$ of two neighboring atoms, where $f_{r}^{E}$ is the frontier electron density of the electrophilic reaction on the $\mathrm{r}$-atom, while $\mathrm{m}$ and $\mathrm{n}$ are the positions of atoms in the double bond [9]. However, electrophilic or nucleophilic reaction on the corresponding aliphatic chain or on aromatic ring is more likely [16].

It is believed that the attack of the electrophilic agent occurs when the energy difference $\Delta \mathrm{E}$ between the LUMO energy of singlet oxygen and HOMO is less than $6 \mathrm{eV}$ [6].

The electron density of the ground HOMO state allows to predict the site of the electrophilic attack, while LUMO—-the site of nucleophilic attack [7] [11].

\section{Experimental}

\section{Molecular Orbital Calculations}

The structure of the tested compounds has been optimized with MM+, DM and AM1 or PM3 (Table 1 and Table 2), to obtain constant energy value. All MO calculations were carried out using HyperChem v.6.0 (Hypercube Inc.). Structure optimization was performed including the standard heats of formation in the gaseous $\mathrm{H}_{\mathrm{f}}$, the energies of highest occupied molecular orbital $\left(\mathrm{E}_{\text {номо }}\right)$ and lowest unoccupied molecular orbital $\left(\mathrm{E}_{\mathrm{LUMO}}\right)$, the electron densities $\left(\mathrm{d}_{\text {номо }}\right)$, the frontier densities $\left(f_{r}^{E}\right.$ and $\left.f_{r}^{N}\right)$ and the dipole moment $(\mu)$ in the gaseous phase, using $\mathrm{AM} 1$ and $\mathrm{PM} 3$ methods [2]. $\mathrm{E}_{\mathrm{LUMO}}{ }^{1} \mathrm{O}_{2}$ equals $-6.51 \mathrm{eV}$ [2].

The calculated HOMO and LUMO energy values of the singlet state of oxygen ${ }^{1} \mathrm{O}_{2}$ are respectively: $-6.294 \mathrm{eV}$ and $-5.339 \mathrm{eV}$ (AM1) as well as $-5.858 \mathrm{eV} \mathrm{i}$ $-5.323 \mathrm{eV}$ (PM3).

Formula and Figure 1 was draw in ISIS Draw v.2.04 program.

\section{Results and Discussion}

In our research we have analyzed photochemical decomposition of ester derivatives of p-hydroxybenzoic acid at the formula [17]:

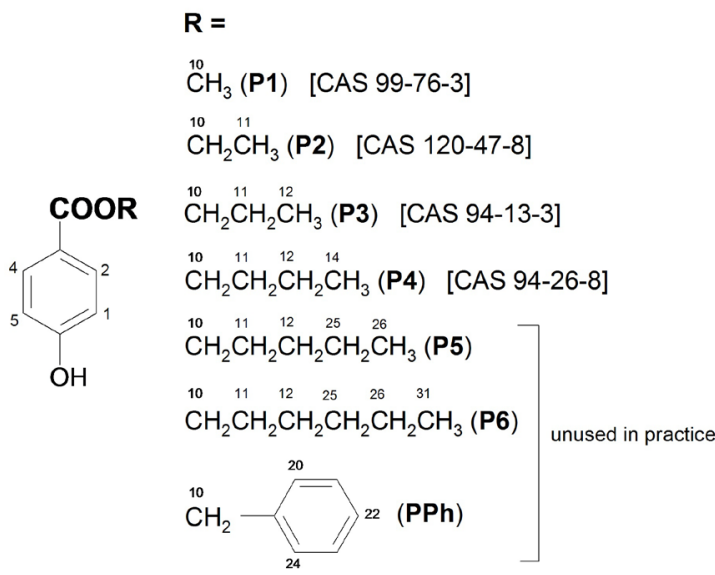




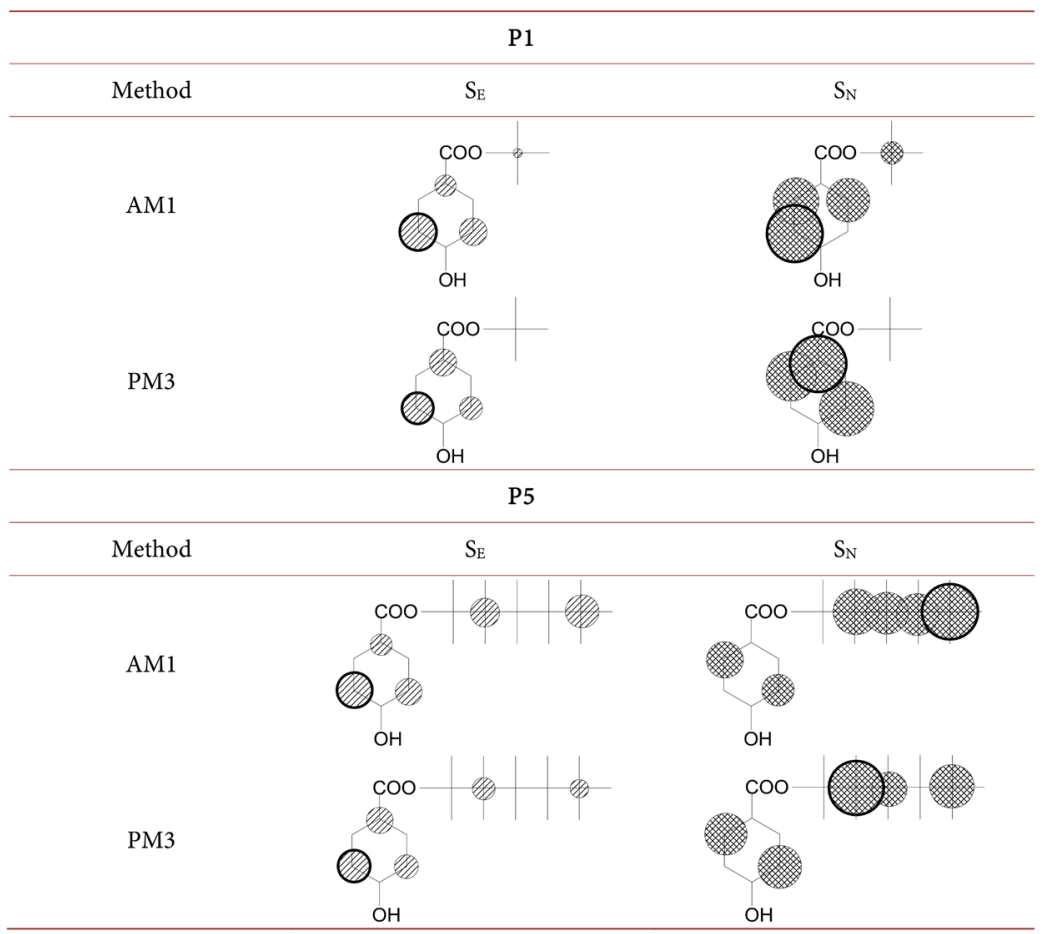

Figure 1. Graphic presentation of superdelocalisabilities $S^{\mathrm{E}}$ and $S^{\mathrm{N}}$ for selected derivatives of PHB-P1 and P5 (atoms numbering-see formula and appropriate values-Table 3). The circle diameter are proportional to the size of the delocalisability of valence electrons in the ground state (HOMO) and excited state (LUMO) and determines the probability of electro- (by ${ }^{1} \mathrm{O}_{2}$ ) or nucleophilic reaction (by $\mathrm{O}_{2}{ }^{--}$). Bold circle means the site of the most probable attack of the oxidizing agent.

Table 1. [AM1] $\mathrm{H}_{\mathrm{f}}$-enthalpy of formation $\left(\mathrm{kcal} \cdot \mathrm{mol}^{-1}\right), \mathrm{HOMO}$ and LUMO energy, $\mathrm{E}_{\mathrm{HOMO}}, \mathrm{E}_{\mathrm{LUMO}}$, $)(\mathrm{eV})$, dipole moment $\mu \mathrm{HOMO}$ and LUMO (debye).

\begin{tabular}{ccccccccc}
\hline & $\mathrm{R}$ & $\mathrm{H}_{\mathrm{f}}$ & $\Delta \mathrm{E}$ & $\mathrm{E}_{\text {HOMO }}$ & $\mathrm{E}_{\mathrm{LUMO}}$ & $\Delta \mathrm{E}_{\mathrm{H}-\mathrm{L}}$ & {$[\mu]_{\text {HOMO }}$} & {$[\mu]_{\mathrm{LUMO}}$} \\
\hline $\mathbf{P 1}^{* 11}$ & $\mathrm{CH}_{3}$ & -106.3468 & 3.675 & -9.5355 & -0.3970 & 9.1385 & 1.398 & 1.535 \\
$\mathbf{P 2}^{* 11}$ & $\mathrm{CH}_{2} \mathrm{CH}_{3}$ & -112.1913 & 3.653 & -9.5132 & -0.3651 & 9.1481 & 2.804 & 2.484 \\
$\mathbf{P 3}$ & $\left(\mathrm{CH}_{2}\right)_{2} \mathrm{CH}_{3}$ & -119.0761 & 3.655 & -9.5151 & -0.3681 & 9.1470 & 2.774 & 2.454 \\
$\mathbf{P 4}$ & $\left(\mathrm{CH}_{2}\right)_{3} \mathrm{CH}_{3}$ & -125.2891 & 3.651 & -9.5113 & -0.3643 & 9.1470 & 1.174 & 1.304 \\
$\mathbf{P 5}^{* 2)}$ & $\left(\mathrm{CH}_{2}\right)_{4} \mathrm{CH}_{3}$ & -131.6912 & 3.653 & -9.5133 & -0.3660 & 9.1473 & 1.285 & 1.428 \\
$\mathbf{P 6}^{* 2}$ & $\left(\mathrm{CH}_{2}\right)_{5} \mathrm{CH}_{3}$ & -138.0849 & 3.653 & -9.5137 & -0.3670 & 9.1467 & 3.017 & 2.705 \\
$\mathbf{P P h}^{* 2}$ & $\mathrm{CH}_{2} \mathrm{Ph}$ & -78.0743 & 3.659 & -9.5191 & -0.3797 & 9.1394 & 1.304 & 1.419
\end{tabular}

Table 2. [PM3] $\mathrm{H}_{\mathrm{f}}$-enthalpy of formation $\left(\mathrm{kcal} \cdot \mathrm{mol}^{-1}\right), \mathrm{HOMO}$ and LUMO energy, $\mathrm{E}_{\mathrm{HOMO}}, \mathrm{E}_{\mathrm{LUMO}}$, $)(\mathrm{eV})$, dipole moment $\mu \mathrm{HOMO}$ and LUMO (debye).

\begin{tabular}{ccccccccc}
\hline & $\mathrm{R}$ & $\mathrm{H}_{\mathrm{f}}$ & $\Delta \mathrm{E}$ & $\mathrm{E}_{\text {Hомо }}$ & $\mathrm{E}_{\mathrm{LUMO}}$ & $\Delta \mathrm{E}_{\mathrm{H}-\mathrm{L}}$ & {$[\mu]_{\text {Hомо }}$} & {$[\mu]_{\mathrm{LUMO}}$} \\
\hline $\mathbf{P 1}^{* 1)}$ & $\mathrm{CH}_{3}$ & -102.8468 & 3.829 & -9.6895 & -0.3016 & 9.3879 & 4.399 & 5.126 \\
$\mathbf{P 2}^{* 1)}$ & $\mathrm{CH}_{2} \mathrm{CH}_{3}$ & -109.2918 & 3.640 & -9.5007 & -0.3157 & 9.1850 & 1.390 & 2.753 \\
$\mathbf{P 3}$ & $\left(\mathrm{CH}_{2}\right)_{2} \mathrm{CH}_{3}$ & -113.5355 & 3.648 & -9.5086 & -0.3432 & 9.1654 & 1.555 & 2.910 \\
$\mathbf{P 4}$ & $\left(\mathrm{CH}_{2}\right)_{3} \mathrm{CH}_{3}$ & -118.9505 & 3.650 & -9.5101 & -0.3223 & 9.1878 & 2.930 & 3.808 \\
\hline
\end{tabular}


Continued

\begin{tabular}{ccccccccc}
\hline $\mathbf{P 5}^{* 2}$ & $\left(\mathrm{CH}_{2}\right)_{4} \mathrm{CH}_{3}$ & -124.9063 & 3.638 & -9.4981 & -0.2740 & 9.2241 & 1.409 & 2.725 \\
$\mathbf{P 6}^{* 2)}$ & $\left(\mathrm{CH}_{2}\right)_{5} \mathrm{CH}_{3}$ & -127.5333 & 3.646 & -9.5060 & -0.3435 & 9.1625 & 1.457 & 2.859 \\
$\mathbf{P P h}^{* 2}$ & $\mathrm{CH}_{2} \mathrm{Ph}$ & -74.5967 & 3.651 & -9.5113 & -0.3623 & 9.1490 & 3.099 & 3.162 \\
\hline
\end{tabular}

$\Delta \mathrm{E}=\mathrm{E}_{\mathrm{LUMO}}$ (singlet oxygen) $-\mathrm{E}_{\mathrm{HOMO}}$ (paraben). LUMO energy of singlet oxygen has been taken from Guo $(=5.860 \mathrm{eV})^{1,2}[6] ; \Delta \mathrm{E}_{\mathrm{H}-\mathrm{L}}-\mathrm{energy}$ difference [HOMO-LUMO], ${ }^{* 1}$ used in practice as mixture, ${ }^{\left.{ }^{*}\right)}$ unused in practice, $\mathrm{Ph}-$ phenyl.

Table 3. Frontier electron density calculation for HOMO and LUMO and superdelocalisability $S^{\mathrm{E}}$ and $S^{\mathrm{N}}$ for selected atoms by AM1 and PM3 methods.

\begin{tabular}{|c|c|c|c|c|c|c|c|c|c|c|c|c|c|}
\hline \multicolumn{7}{|c|}{ AM1 } & \multicolumn{7}{|c|}{ PM3 } \\
\hline & Atom & $\mathrm{AO}$ & $S^{E}$ & Atom & $\mathrm{AO}$ & $S^{N}$ & & Atom & $\mathrm{AO}$ & $\mathrm{S}^{\mathrm{E}}$ & Atom & $\mathrm{AO}$ & $\mathrm{S}^{\mathrm{N}}$ \\
\hline \multirow{3}{*}{ P1 } & 1 & -0.1775 & 0.0372 & 2 & -0.1161 & 0.5847 & \multirow{3}{*}{ P1 } & 1 & -0.1488 & 0.0307 & 1 & -0.1132 & 0.7504 \\
\hline & 3 & -0.1535 & 0.0322 & 4 & -0.1222 & 0.6158 & & 3 & -0.1854 & 0.0383 & 3 & -0.1455 & 0.9646 \\
\hline & 5 & -0.2332 & 0.0489 & 5 & -0.1460 & 0.7355 & & 5 & -0.2028 & 0.0419 & 4 & -0.1105 & 0.7328 \\
\hline \multirow{4}{*}{ P2 } & 1 & -0.1755 & 0.0369 & 1 & -0.1474 & 0.8074 & \multirow{4}{*}{ P2 } & 1 & -0.1613 & 0.0339 & 1 & -0.1203 & 0.7623 \\
\hline & 3 & -0.1538 & 0.0323 & 2 & -0.1204 & 0.6597 & & 3 & -0.1708 & 0.0359 & 4 & -0.1111 & 0.7037 \\
\hline & 5 & -0.2354 & 0.0495 & 4 & -0.1176 & 0.6443 & & 5 & -0.2129 & 0.0448 & 11 & -0.1471 & 0.9317 \\
\hline & 11 & -0.2445 & 0.0514 & 11 & -0.2436 & 1.3342 & & 11 & -0.1475 & 0.0311 & & & \\
\hline \multirow{4}{*}{ P3 } & 1 & -0.1755 & 0.0369 & 1 & -0.1474 & 0.8074 & \multirow{4}{*}{ P3 } & 1 & -0.1625 & 0.0342 & 1 & -0.1207 & 0.7029 \\
\hline & 5 & -0.2354 & 0.0495 & 4 & -0.1380 & 0.7495 & & 3 & -0.1709 & 0.0359 & 4 & -0.1128 & 0.6572 \\
\hline & 11 & -0.1911 & 0.0402 & 11 & -0.1908 & 1.0367 & & 5 & -0.2139 & 0.0449 & 11 & -0.1075 & 0.6263 \\
\hline & 13 & -0.2085 & 0.0438 & 12 & -0.2082 & 1.1312 & & 12 & -0.1102 & 0.0232 & 12 & -0.1098 & 0.6396 \\
\hline \multirow{5}{*}{ P4 } & 1 & -0.1777 & 0.0374 & 1 & -0.1466 & 0.8047 & \multirow{4}{*}{ P4 } & 1 & -0.1595 & 0.0335 & 1 & -0.1201 & 0.7454 \\
\hline & 5 & -0.2333 & 0.0491 & 4 & -0.1353 & 0.7429 & & 3 & -0.1694 & 0.0356 & 4 & -0.1188 & 0.7369 \\
\hline & 11 & -0.1901 & 0.0399 & 11 & -0.1897 & 1.0411 & & 5 & -0.2144 & 0.0451 & 11 & -0.1159 & 0.7191 \\
\hline & 12 & -0.1538 & 0.0323 & 14 & -0.2126 & 1.1673 & & & & & 14 & -0.1143 & 0.7089 \\
\hline & 14 & -0.2130 & 0.0448 & & & & \multirow{5}{*}{ P5 } & 1 & -0.1582 & 0.0333 & 1 & -0.1198 & 0.8741 \\
\hline \multirow{5}{*}{ P5 } & 1 & -0.1777 & 0.0374 & 11 & -0.1865 & 1.0188 & & 3 & -0.1687 & 0.0355 & 4 & -0.1114 & 0.8129 \\
\hline & 3 & -0.1539 & 0.0324 & 12 & -0.1588 & 0.8677 & & 5 & -0.2108 & 0.0444 & 11 & -0.1474 & 1.0756 \\
\hline & 5 & -0.2333 & 0.0490 & 25 & -0.1588 & 0.8678 & & 11 & -0.1480 & 0.0312 & 26 & -0.1210 & 0.8833 \\
\hline & 11 & -0.1870 & 0.0393 & 26 & -0.2102 & 1.1483 & & 26 & -0.1204 & 0.0254 & & & \\
\hline & 26 & -0.2104 & 0.0442 & & & & \multirow{5}{*}{ P6 } & 1 & -0.1629 & 0.0343 & 1 & -0.1207 & 0.7027 \\
\hline \multirow{4}{*}{ P6 } & 1 & -0.1753 & 0.0369 & 1 & -0.1470 & 0.8007 & & 3 & -0.1722 & 0.0362 & 4 & -0.1127 & 0.6558 \\
\hline & 3 & -0.1533 & 0.0322 & 4 & -0.1371 & 0.7470 & & 5 & -0.2143 & 0.0451 & 11 & -0.1302 & 0.7576 \\
\hline & 5 & -0.2353 & 0.0495 & 31 & -0.2098 & 1.1430 & & 11 & -0.1299 & 0.0273 & 31 & -0.1084 & 0.6308 \\
\hline & 31 & -0.2100 & 0.0441 & & & & & 31 & -0.1088 & 0.0229 & & & \\
\hline \multirow{5}{*}{$\mathrm{PPh}$} & 1 & -0.1777 & 0.0373 & 1 & -0.1458 & 0.7680 & \multirow{5}{*}{$\mathrm{PPh}$} & 1 & -0.1617 & 0.0340 & 1 & -0.1604 & 0.8854 \\
\hline & 3 & -0.1539 & 0.0323 & 4 & -0.1343 & 0.7076 & & 3 & -0.1723 & 0.0362 & 3 & -0.1705 & 0.9410 \\
\hline & 5 & -0.2336 & 0.0399 & 21 & -0.1381 & 0.7275 & & 5 & -0.2164 & 0.0455 & 5 & -0.2151 & 1.1873 \\
\hline & 21 & -0.1376 & 0.0289 & 23 & -0.1357 & 0.7150 & & 21 & -0.1074 & 0.0226 & 21 & -0.1003 & 0.5534 \\
\hline & 23 & -0.1351 & 0.0284 & & & & & 23 & -0.1078 & 0.0227 & 22 & -0.1013 & 0.5592 \\
\hline
\end{tabular}

${ }^{1} \mathrm{E}_{\text {LUMO }}\left({ }^{1} \mathrm{O}_{2}\right)=-6.51 \mathrm{eV}[2]$.

${ }^{2}$ Calculated $\mathrm{E}_{\mathrm{LUMO}}$ of singlet oxygen ${ }^{1} \mathrm{O}_{2}=6.294 \mathrm{eV}$ (AM1) or $5.858 \mathrm{~V}$ (PM3). 
$\Delta \mathrm{E}_{\mathrm{H}-\mathrm{L}}$ allows to determine range of wavelengths at which the PHB derivatives will be able to occur in the excited LUMO state and react with the electrophilic agent. The HOMO-LUMO energy difference range is approximately $9.51 \div 9.54$ $\mathrm{Ev}$, corresponding to the calculated absorption range of electromagnetic radiation of wavelength $\lambda_{\max }=322.9 \div 331.6 \mathrm{~nm}$ (PPh $266.0 \mathrm{~nm}$ ) [AM1]. P1 and PPh derivatives are easiest to excite, while it is more difficult with aliphatic chains in ester residue. Similar dependencies are observed for PM3 calculations, respectively $9.16-9.69 \mathrm{eV}$ for the calculated absorption range of $\lambda_{\max }=317.9-318.2$ $\mathrm{nm}(\mathrm{PPh} 263.1 \mathrm{~nm})$.

The electron density of frontier HOMO and LUMO states has been calculated. Sites with highest electron density and superdelocalisability indicate prospective sites for electrophilic or nucleophilic oxidation reaction.

Light fastness can be tested for the possibility of an electrophilic or nucleophilic attack of the oxidizing agent. The analysis of $\Delta \mathrm{E}$ changes, frontier electron densities HOMO and LUMO, along with respective superdelocalisabilities $S^{\mathrm{E}}$ and $\mathrm{S}^{\mathrm{N}}$ may explain light resistance of parabens in a satisfactory manner.

Table 1 present $S^{\mathrm{E}}$ HOMO and $S^{\mathrm{N}}$ LUMO values, which allow to predict the prospective site of attack by singlet oxygen ${ }^{1} \mathrm{O}_{2}$, or superoxide anion radical $\mathrm{O}_{2}{ }^{\cdot-}$. High $\mathrm{S}^{\mathrm{E}}$ and $\mathrm{S}^{\mathrm{N}}$ indicate high likelihood of reaction on a given carbon atom. On Figure 1 a graphical presentation of calculation results of chosen PHB derivatives $-\mathrm{P} 1$ and $\mathrm{P} 5$ is shown, to illustrate differences in the oxidation mechanism of a photochemical decomposition.

The analysis of superdelocalisability changes in the P1 compound done using AM1 and PM3 suggest the mechanism of electrophilic oxidation reaction according to 5-addition and should lead to the decomposition of the aromatic ring. The side chain of ester group does not take part in this reaction. Nucleophilic reactions should occur primarily in positions 4-, 5-. In AM1 method, positions 2- and 4- have similar reactivity.

\subsection{Results}

The theoretical methods are a significant contribution to understanding the physiochemical properties of compounds. In this paper, we have tried to investigate the photochemical distribution of parabens with quantum-chemical calculations, allowing deeper insight into the process itself. The calculation methods have been previously described. The parameters for theoretical calculations are frontier electron densities of HOMO and LUMO orbitals [7] [18].

A theoretical study of photofading processes has been very widely used in the analysis of organic dyes degradation, due to their common practical application; the purpose of the study was the identification and root cause analysis for the toxicity of their degradation products [19] [20].

In our analysis, we focused on the determination of prospective attack sites of the oxidizing agent on the molecule of parabens derivative (4-hydroxybenzoic acid), including into considerations the derivatives used as anti-oxidants in the cosmetics industry. Cosmetics and their additives, in result of oxidation, espe- 
cially with regards to trace amounts of metals, may be oxidized to superoxides. Thin layers of cosmetics applied to the skin are particularly exposed to light, heat and oxygen from the air. The characteristic feature of PHB is their ease of oxidation, greater than the applied compounds have. At the same time, their toxicity is low or none in contact with human skin. Thanks to the ease of oxidation, they limit the possibility of harmful products formation, resulting from photooxidation of cosmetics, where the products are compounds toxic to human skin. Additionally, parabens are used as bacteriostatic ingredient.

To understand the dependence of light fastness of the tested derivatives, one needs first to find the location of the most reactive site and then correlate the calculated values with experimental results which, however, is not always possible [1]. In turn, the length of the alkyl chain of the ester residue has impact on the changes in electron density and the longer it is the stronger is the nucleophilic nature of the -COO- moiety.

The methods selected for calculation-AM1 and PM3-belong to the most advanced ones, applied for quantum-chemical analyses and to determine the reactivity of chemical compounds. AM1 makes it possible to explore the geometry of the molecule and correctly predict many physical and chemical properties; while PM3 is used to confirm the accuracy of the AM1 calculations [13]. Both methods indicate, to varying degrees, the similar sites of electro- $\left({ }^{1} \mathrm{O}_{2}\right)$ or nucleophilic $\left(\mathrm{O}_{2}{ }^{--}\right)$attack. Computational methods allow to predict the fastness of chemical compounds to oxidation, including even those which cannot exist as mixtures of different chemical structures, and help understand the mechanism of photochemical degradation along with the impact of substituents on reaction rates [1].

The results obtained in the course of calculations indicate not only the probable sites of reaction for the oxidizing agent in electrophilic and nucleophilic reactions, but also allow for comparison between them. Such analysis helps to find out about the reactivity of a given molecule and select an appropriate compound for required purpose. The applied methods differ in assumptions and results obtained.

\subsection{Analysis by AM1 Method}

The analysis indicates that the most reactive sites are carbon atoms in position 5of the aromatic ring (exception of P2) and their reactivity is dependent on the length of the aliphatic chain in ester residue. The reactivity of position 5- in an electrophilic reaction can be ranked as follows:

$$
\mathrm{P} 2=\mathrm{P} 3>\mathrm{P} 6>\mathrm{P} 4 \approx \mathrm{P} 5>\mathrm{P} 1>\mathrm{PPh}
$$

The carbon atom $\mathrm{C}_{5}$ has highest value $\mathrm{S}^{\mathrm{E}}$ as compared to other atoms, where the difference decreases with the length of the aliphatic chain. The longer the chain the lower the value and the higher the probability of reaction in the aliphatic chain than in the PHB phenyl ring. The exception is $\mathbf{P} 2$, where the reaction should first should occur on the $\mathrm{C}_{11}$ carbon atom (see formula), of the ali- 
phatic chain. The difference in reactivity to $\mathrm{C}_{5}$ is about $3.7 \%$. What also draws attention is the very low reactivity of the phenyl ring ester residue in $\mathrm{PPh}$, lower even than the on carbon $\mathrm{C}_{1}$ of the paraben. The reaction mechanism of electrophilic oxidation by ${ }^{1} \mathrm{O}_{2}$ probably takes place via the stadium of superoxide derivative [16].

The nucleophilic oxidation reaction by superoxide radical and the nucleophilic oxidation reaction of the susuperoxide radical $\mathrm{O}_{2}{ }^{--}$shows high reactivity of the methyl residue $-\mathrm{CH}_{3}$ of group $\mathrm{C}_{11}-\mathrm{C}_{31}$ (see formula). It may be ranked in the following order:

\section{P2 $>$ P4 > P3 > P5 > P6 > PPh $>$ P1}

In nucleophilic oxidation the most important are the alkyl residues of the ester group and the reaction should occur in the first place on the methyl group $-\mathrm{CH}_{3}$, closing the aliphatic chain. The exception is compound P1, where the methyl group is directly linked to ester residue -COO-. This results in a significant reduction in its electron density in the excited state of LUMO.

Exceptions to the above are $\mathbf{P} \mathbf{1}$ and $\mathbf{P} 2$, where the reaction should occur on the PHB phenyl ring. The sites of the highest $\mathrm{S}^{\mathrm{H}}$ value are in general carbon positions $\mathrm{C}_{11}-\mathrm{C}_{31}$ (see formula) in an aliphatic chain, and they are methyl residues $-\mathrm{CH}_{3}$, similarly as in the nucleophilic reaction. In the aromatic ring, carbons $\mathrm{C}_{1}$ and $\mathrm{C}_{4}$ are characterized by high reactivity, however it is not high enough for the reaction to occur on these carbon atoms. In $\mathbf{P} 1$ and $\mathbf{P} 2$ significant $S^{N}$ values are observed on neighboring carbon atoms in the PHB ring $\left(\mathrm{C}_{4}, \mathrm{C}_{5}\right.$ in $\mathrm{P} 1$ and $\mathrm{C}_{1}, \mathrm{C}_{2}$ in P2) which can lead to the degradation of the aromatic ring by 1,2 -addition (Diels-Alder reaction) [7] [22]. Such reaction mechanism is most probable for P1.

The PPh derivatives are characterized by low reactivity; the reaction should occur on carbon atom $\mathrm{C}_{1}$, whereas similar $\mathrm{S}^{\mathrm{N}}$ values have carbon atoms $\mathrm{C}_{21}$ and $\mathrm{C}_{23}$, where the differences as compared to $\mathrm{C}_{1}$ are respectively, $5.3 \%$ and $6.9 \%$ and the reaction should occur through the formation of superoxides.

Similarly to the electrophilic reaction, the reactivity of $\mathbf{P} \mathbf{1}$ and $\mathbf{P P h}$ derivatives is low; it is difficult to subject them to nucleophilic oxidation reaction with a superoxide radical $\mathrm{O}_{2}^{--}$. In the remaining derivatives, the oxidation reaction would occur or the methyl group on the aliphatic chain of the ester residue.

\subsection{Analysis by PM3 Method}

The results of calculations made by PM3 indicate a similar electrophilic reaction mechanism $S^{\mathrm{E}}$ as described for AM1. High electron density of the basic HOMO state occurs on atoms $\mathrm{C}_{1}-\mathrm{C}_{5}$ in the phenyl ring of the paraben. In all cases, the reaction should occur on carbon atom $\mathrm{C}_{5}$. The reactivity of compounds P1 - P6, $\mathrm{PPh}$ can be ranked in the following order:

$\mathrm{PPh}>\mathrm{P} 4 \approx \mathrm{P} 6>\mathrm{P} 3>\mathrm{P} 2>\mathrm{P} 5>\mathrm{P} 1$

This method shows yet another possibility for the reaction to occur on $\mathrm{C}_{3}$ atom, where the $\Delta S^{\mathrm{E}}$ values differ by about $0.08-0.1$ from the values calculated for $\mathrm{C}_{5}$. This method confirms the direction of oxidative decay of PHB obtained 
by AM1. The reaction mechanism probably takes place by the stadium of peroxide derivatives [16]. In the nucleophilic oxidation by superoxide radical $\mathrm{O}_{2}{ }^{--}$ the reaction rate may be ranked in the following order $\left(S^{N}\right)$ :

PPh > P5 > P2 > P1 > P4 > P3 > P6

However, the conclusions to these calculations are not entirely clear. This reaction may occur in both methyl residues $-\mathrm{CH}_{3}(\mathrm{P} 2, \mathrm{P} 4)$ and methylene residues $-\mathrm{CH}_{2}-(\mathrm{P} 5, \mathrm{P} 6)$ of the aliphatic chain of the ester residue. The reaction mechanism is similar to the one proposed in AM1, i.e. through the superoxide intermediate reaction stage [16]. The exceptions would be $\mathrm{P} 1$ reactions, where one should expect 1,2-addition to the PHB phenyl ring [7] [22]. High superdelocalisability coefficients are in atoms $\mathrm{C}_{1}$ and $\mathrm{C}_{2}$ and this reaction direction should be privileged. In $\mathrm{PPh}$ these coefficients are high for $\mathrm{C}_{1}, \mathrm{C}_{3}$ and $\mathrm{C}_{5}$. The characteristic feature of the PM3 calculations for all derivatives are high reactivity coefficients of carbon atoms $\mathrm{C}_{1}$ and $\mathrm{C}_{4}$, which makes them different from AM1 calculations. However they do not determine the direction of reaction, which according to the proposed order is mainly on the alkyl ester residue.

\section{Conclusions}

The ease of oxidation is determined by the energy difference $\Delta \mathrm{E}$ of the highest occupied molecule orbital $\left(\mathrm{E}_{\mathrm{HOMO}}\right)$ the lowest unoccupied molecule orbital $\left(\mathrm{E}_{\text {LUMO }}\right)$ of singlet oxygen ${ }^{1} \mathrm{O}_{2}$.

This difference indicates that the tested compounds are easily subject to photofading, since the $\Delta \mathrm{E}$ values are lower than the minimal energy value for oxidation which is ca. $6 \mathrm{eV}$ [1] [3]. They are 3.651 - $3.675 \mathrm{eV}$ (AM1) and 3.829 $3.638 \mathrm{eV}(\mathrm{PM} 3)$ when $\mathrm{E}_{\mathrm{LUMO}}{ }^{1} \mathrm{O}_{2}=5.860 \mathrm{eV}[3]$. Hence $\Delta \mathrm{E}$ are $3.217 \div 3.239 \mathrm{eV}$ (AM1) and 3.640 - $3.831 \mathrm{eV}$ (PM3), including values calculated with quantum-chemical methods AM1 and PM3. In each case $\Delta \mathrm{E}$ are lower than the reaction energy frontier values $=6 \mathrm{eV}$.

Among the analyzed compounds, commercial use has been found for P3, P4, $\mathbf{P 5}, \mathbf{P P h}$. The analysis shows that similar preserving properties may also be found in derivatives of P2 (AM1, electrophilic and nucleophilic reactions) and P6 (AM1, electrophilic reaction), while oxidation should occur also on atom $\mathrm{C}_{5}$ of the aromatic ring of the P6 derivative, while in P2 the methyl group of ester residue is most reactive. It is also the most reactive of all tested derivatives $S^{\mathrm{E}} \cong$ 0.0514 to $S^{\mathrm{E}} \cong 0.0495$ in other derivatives on atom in the PHB aromatic ring. The most probable oxidation mechanism includes the attack of singleton oxygen $\left({ }^{1} \mathrm{O}_{2}\right)$ on the molecule of the compound and the formation of superoxide derivatives. In the course of the reaction, epoxide derivatives may form [16]. Alicyclic superoxide may form temporarily, which after dehydration gives unsaturated ketone or may be reduced to allyl alcohol.

The reaction mechanism has not yet been thoroughly explained so far. Chemical compounds that generate singlet oxygen ${ }^{1} \mathrm{O}_{2}$ (e.g. sensitizers) in contact with the skin accelerate the destruction nucleic acids and enzymes, and thus can lead to cancer skin changes [21] [22]. 
Among the tested PHB derivatives $\mathbf{P} 1$ is not recommended for practical use, as its photochemical decomposition may lead to the danger of methyl alcohol formation. Besides, the performed analysis shows that it does not have the highest antioxidant properties (worse is only $\mathrm{PPh}$ in the electrophilic reaction) in the tested group of derivatives.

Both AM1 and PM3 methods in many points show similar most probable sites of electrophilic or nucleophilic attack on the PHB molecule. In the electrophilic reaction, it will be the PHB aromatic ring, in the nucleophilic one-the alkyl group in the ester residue.

The results and conclusions of these studies, initiated by a research on organic dyes, may help explain the mechanism of photofading of parabens used as conservatives in cosmetics. Understanding the mechanism of their photodegradation will help to improve the process of their more accurate selection to protect the chemical compounds that remain in direct contact with the skin.

The calculations show that the method of predicting the properties and correlations with calculated values of electron density and energy of ground HOMO and excited LUMO states ... etc. has a range of limitations. However, they enable deeper insight into the reaction of photochemical decomposition reaction and can be used to test different compounds.

\section{Conflicts of Interest}

The authors declare no conflicts of interest regarding the publication of this paper.

\section{References}

[1] Tripathi, S., Vasudev, I. and Ray, A. (2008) Photofading of Azo Dyes: A Theoretical Study. Coloration Technology, 124, 151. https://doi.org/10.1111/j.1478-4408.2008.00135.x

[2] Hihara, T., Okada, Y. and Morita, Z. (2003) Reactivity of Phenylazonaphthol Sulfonates, Their Estimation by Semiempirical Molecular Orbital PM5 Method, and the Relations between Their Reactivity and Azo-Hydrazone Tautomerism. Dyes and Pigments, 59, 201. https://doi.org/10.1016/S0143-7208(03)00109-8

[3] Özen, A.S., Aviyente, V. and Klein, R.A. (2003) Modeling the Oxidative Degradation of Azo Dyes: Density Functional Theory Study. Journal of Physical Chemistry $A, 107,4898$. https://doi.org/10.1021/jp026287z

[4] Morley, J.O., Guy, O.J. and Charlton, M.H. (2004) Molecular Modeling Studies on the Photochemical Stability of Azo Dyes. Journal of Physical Chemistry A, 108, 10542. https://doi.org/10.1021/jp0470010

[5] Ray, A. and Deheri, G.M. (1995) CNDO/II Study on the Fading of Antraquinone Dyes. Dyes and Pigments, 27, 327. https://doi.org/10.1016/0143-7208(94)00069-E

[6] Guo, L., Meng, F.S., Gong, X.D., Xiao, X.M., Cheng, K.C. and Tian, H. (2001) Synthesis and Spectral Properties of Soluble Trimethylsilyl Substituted Metal-Phthalocyjanines. Dyes and Pigments, 49, 83. https://doi.org/10.1016/S0143-7208(01)00011-0

[7] Wang, L.F., Wang, X.L. and Zhang, H.Y. (2005) A Theoretical Study on Photobleaching Mechanisms of Hypocrellins. Dyes and Pigments, 67, 161. https://doi.org/10.1016/j.dyepig.2004.11.007 
[8] Fukui, K., Yonezawa, T. and Nagata, C. (1957) MO-Theoretical Approach to the Mechanism of Charge Transfer in the Process of Aromatic Substitutions. Bulletin of the Chemical Society of Japan, 27, 1247.

[9] Okada, Y., Hihara, T., Hirose, M. and Morita, Z. (2010) Substituent Effects on the Photofading of Disperse Azo Dyes on Poly(ethylene terephthalate) Substrate. Coloration Technology, 126, 127. https://doi.org/10.1111/j.1478-4408.2010.00237.x

[10] Özen, A.S., Aviyente, V. and Klein, R.A. (2004) Modeling the Substituent Effect on the Oxidative Degradation of Azo Dyes. Journal of Physical Chemistry A, 108, 5990. https://doi.org/10.1021/jp037138z

[11] Morita, Z. and Hada, S. (1999) A Semiempirical Molecular Orbital Study on the Reaction of an Aminopyrazolinyl Azo Dye with Singlet Molecular Oxygen. Dyes and Pigments, 41, 1. https://doi.org/10.1016/S0143-7208(98)00038-2

[12] Fukui, K. and Yonezawa, T. (1957) C Nagata, Interrelation of Quantum-Mechanical Quantities Concerning Chemical Reactivity of Conjugated Molecules. Journal of Chemical Physics, 26, 831. https://doi.org/10.1063/1.1743416

[13] Dewar, M.J.S., Zoebisch, E.G., Hearly, E.R. and Steward, J.J.P. (1985) The Development and Use of Quantum-Mechanical Molecular Models. 76. AM1: A New General Purpose Quantum Mecanical Molecular Model. Journal of American Chemical Society, 107, 3902. https://doi.org/10.1021/ja00299a024

[14] Dewar, M.J.S. and Thiele, W. (1975) Ground-States of Molecules .30. Mindo-3 Study of Reactions of Singlet (1-Delta-g) Oxygen with Carbon-Carbon Double-Bonds. Journal of American Chemical Society, 97, 3978.

https://doi.org/10.1021/ja00847a018

[15] Hihara, T., Okada, Y. and Morita, Z. (2004), Relationship between Photochemical Properties and Colourfastness Due to Light-Related Effects on Monoazo Reactive Dyes Derived from H-Acid, $\gamma$-Acid, and Related Naphthalene Sulfonic Acids. Dyes and Pigments, 59, 269.

[16] Griffiths, J. and Hawkins, C. (1976) Oxidation by Singlet Oxygen of Arylazonaphthols Exhibiting Azo-Hydrazone Tautomerism. Journal of the Chemical Society, Perkin Transactions II, 747-752.

[17] Commission Regulation (EU) No. 358/2014, Official Journal of the EU, L 107 (Vol. 57), 10 April 2014. https://green.pidc.org.tw/upload/news/OJ-JOL_2014_107_R_0002-EN-TXT

[18] Wang, X.L., Wang, L.F. and Zhang, H.Y. (2004) A Theoretical Study on Isomerisation Process of Hypocrellin A in Ground State. Dyes and Pigments, 63, 23-28. https://doi.org/10.1016/j.dyepig.2004.01.003

[19] Vanbeek, H.C.A. and Heertjes, P.M. (1966) The Mechanism of the Photoreduction of Azo Dyes in the Presence of DL-Mandelic Acid and in the Absence of Oxygen. Journal of Physical Chemistry, 70, 1704-1711. https://doi.org/10.1021/j100878a004

[20] Biswas, N. and Umpathy, S. (1999) Structures, Vibrational Frequencies, and Normal Modes of Substituted Azo Dyes: Infrared, Raman, and Density Functional Calculations. Journal of Physical Chemistry, 104, 2734-2745. https://doi.org/10.1021/jp9929263

[21] Foote, C.S. (1968) Photosensitised Oxygenations and the Role of Singlet Oxygen. Accounts of Chemical Research, 1, 104-110. https://doi.org/10.1021/ar50004a002

[22] Matsuura, T. (1977) Bio-Mimetic Oxygenation. Tetrahedron, 33, 2869-2905. https://doi.org/10.1016/0040-4020(77)88020-4 